Youssef Khalaf MAHAL ${ }^{1}$ \& Hamid Abdullah SALEH ${ }^{2}$

\title{
THE MORPHOLOGICAL CONTROVERSY OF MUHAMMAD BIN MUSTAFA AL-TAUSKARI IN HIS BOOK (BADAH AL-MUKTAFI FI SHARH KIFAYA AL-MUBTADI)
}

\section{Istanbul / Türkiye}

\section{p. $37-42$}

\section{Article Information}

Article Type: Research Article This article was checked by iThenticate No plagiarism detected

\section{Article History}

Received: 03/08/2021

Accepted: $10 / 08 / 2021$

published: 01/09/2021

\begin{abstract}
:
Disagreement occurred between the Basri and Kufi doctrines, in many branches, and each of them went to support his doctrine according to the method that he followed with textual and rational evidence, and the difference increased and raged between them for a long time, and the early scholars alerted to this grammatical dispute, and the first to write about it was a fox ( D. $291 \mathrm{AH}$ ) wrote his book (The Difference of Grammarians), then after that synonymous and successive books, hence my research was called (the morphological dispute at Al-Tauskari in his book Bada'a Al-Muktafi fi explaining the adequacy of Al-Mubtadi), and it included three sections that were previously translated by the author, and a foreword to the grammatical dispute, and dealt with In the first topic: the controversial issues that he preferred, while the second topic included the controversial issues that the author left without weighting, and the third topic is the issues that were called the agreement between scholars and they are originally in dispute: This research is on a number of Arabic sources, the most important of which are: Sibawayh's book, al-Muqtadat, Usul fi Grammar, Explanation of the Mufassal, Rashish for beating, and other sources.
\end{abstract}

Key words: The Morphological Controversy, Muhammad Bin Mustafa Al-Tauskari, Grammarians.

http://dx.doi.org/10.47832/2791-9323.3-2.3

Prof. Dr. , Iraqi University, Iraq, dryousif180@gmail.com, https://orcid.org/0000-0002-4440-431X

2 (iD) Researcher, Iraqi University, Iraq, hamedalabd589@gmail.com 


\title{
الخلاف الصرفي عند محمد بن مصطفى الطاوسكاري في كتابه (بضاعة المكتفي في شرح كفاية المبتدي)
}

\section{يوسف خلف محل 3 \\ حميد عبدالله صالح 4}

\begin{abstract}
الملخص

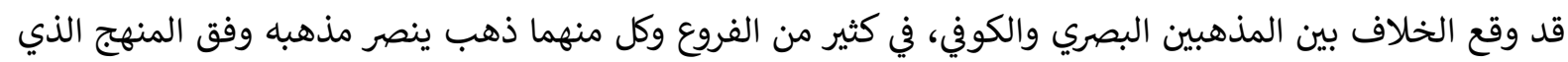

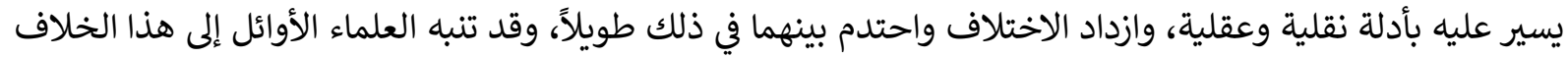

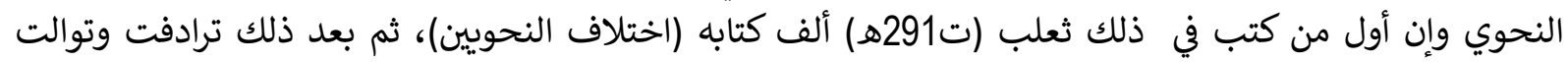

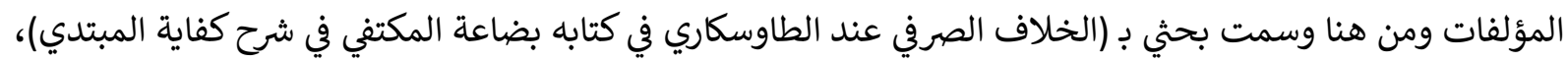

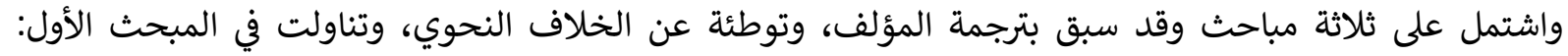

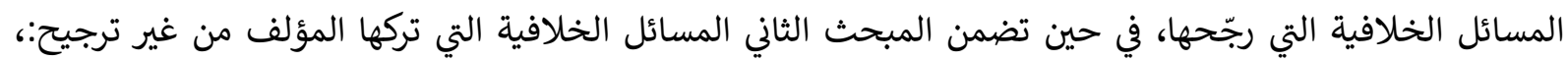

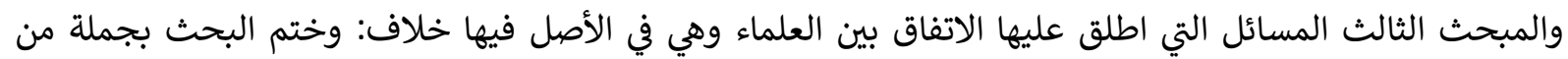

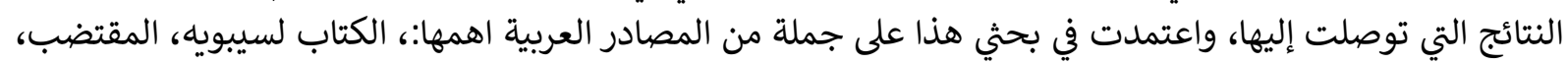

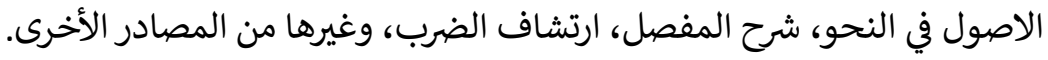
الكلمات المفتاحية: الخلاف الصرفي، محمد بن مصطفى الطاوسكاري، النحويين.
\end{abstract}

المقدمة:

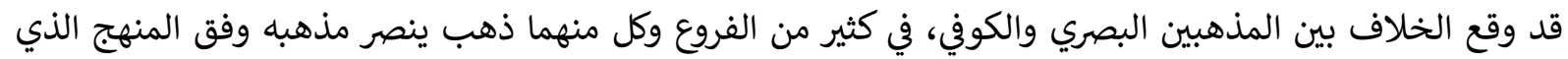

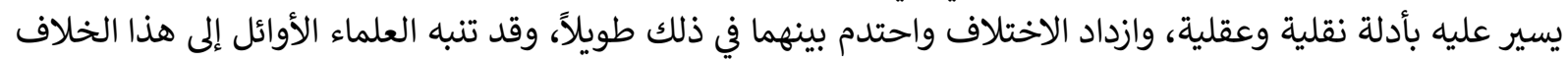

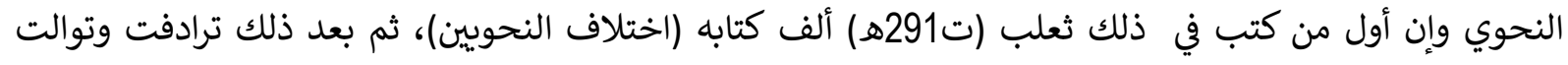

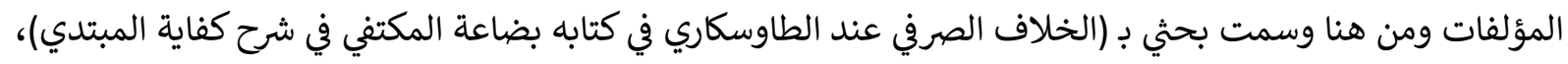

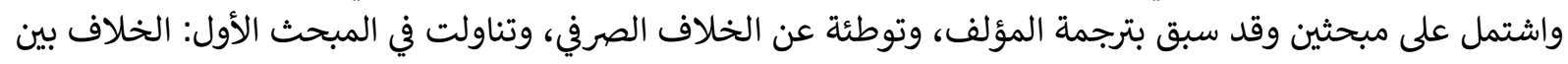

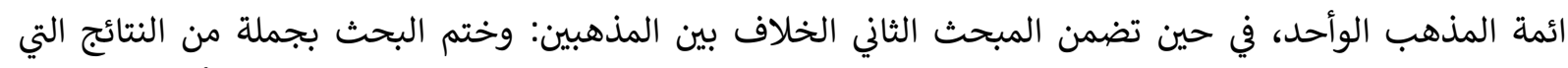

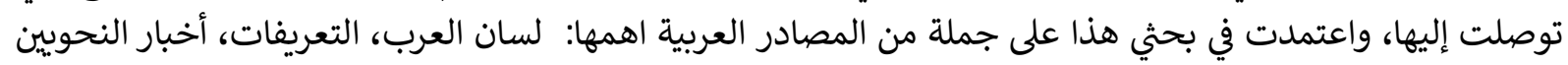
البصريين، وغيرها من المصادر الأخرى.

ترجمة المؤلِّف:

المؤلف: محمد البلوري الطاوسكاري .

هو محمد بن مصطفى البلوري المتوفى سنة 1161 هـ أحدى وستين ومائة والف للهجرة، الموافق (1748) الف الف الفودئ وسبعمائة وثمان وأربعون للميلاد .

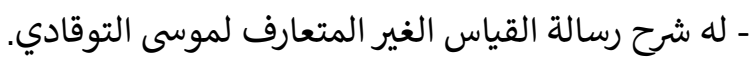
وهو من العلماء المغمورين الذين لم تذكر عنهم كتب التراجم الكثير ولم يتم تسليط الضوء علئي عليهم من قبل الباحثين

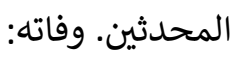
كانت وفاته في سنة ثمان وعشرين ومائة وألف، ودفن بحلب الشهباء رحمه الله تعإلى . 


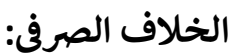

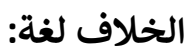

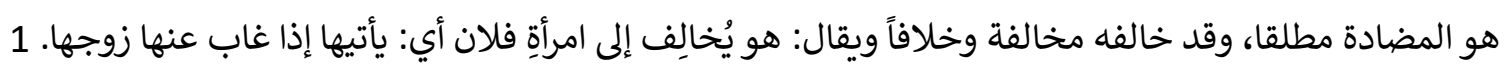

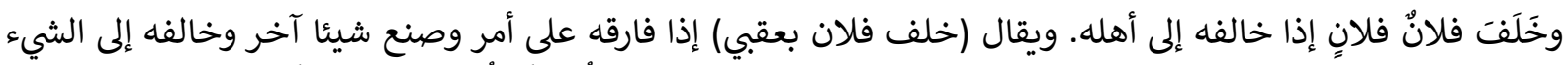

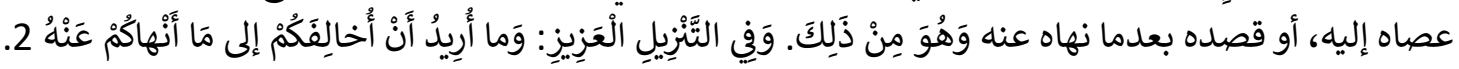

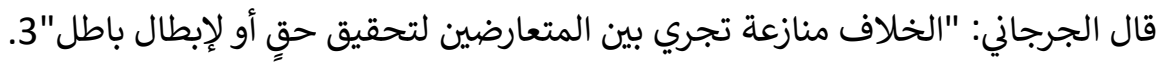

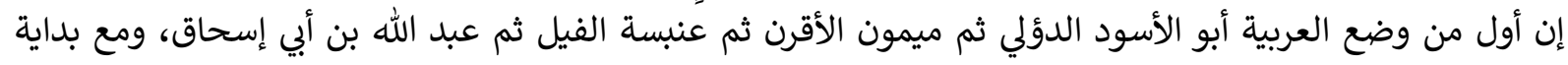

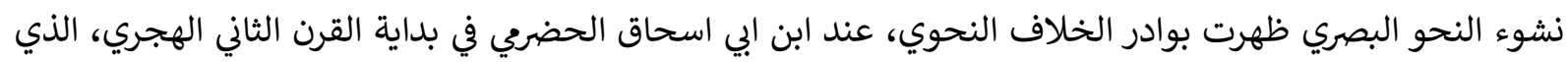

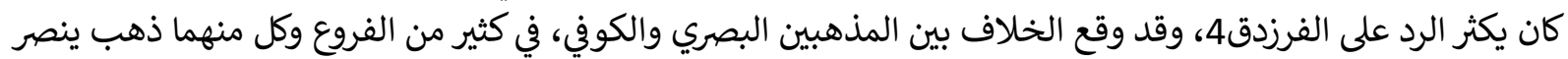

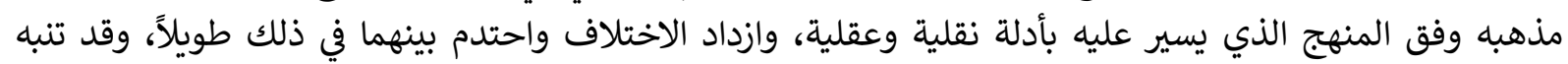

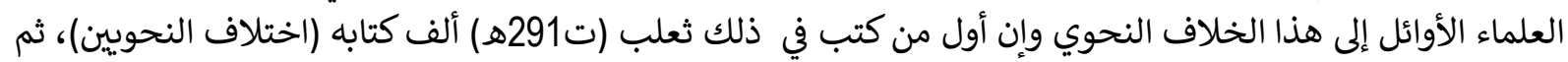

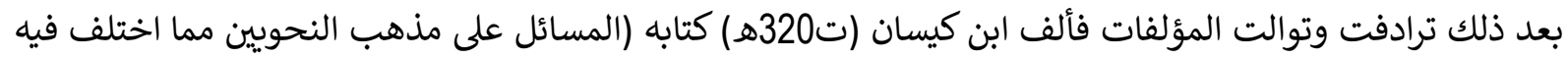

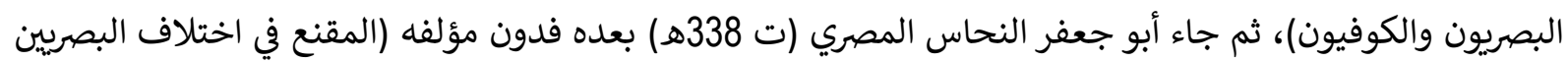

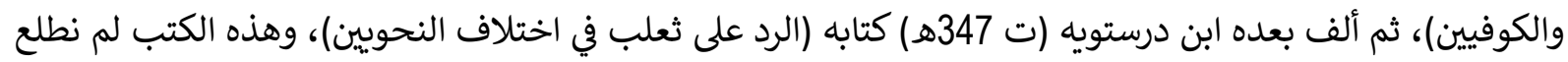

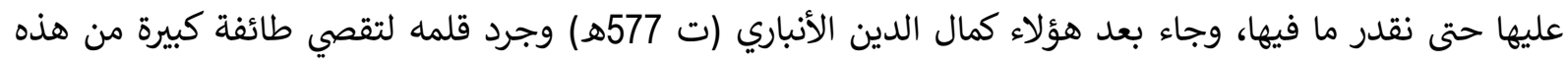

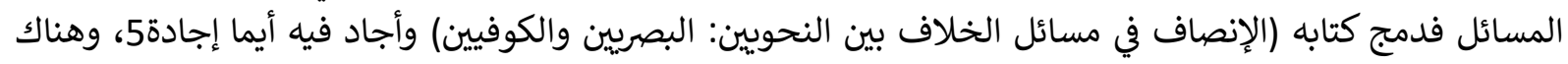

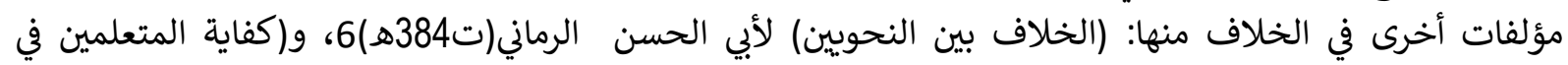

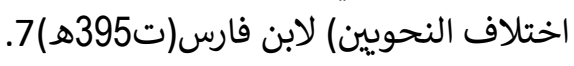
أما موقف الشيخ الطاوسكاري من الخلاف فارفارف في كتابه (بضاعة المكتفي في شرح كفاية المبتدي) فقد تمت الأشارة إليه في مواضع عدة، منها خلاف أئمة المذهب الوأحلد الخد، ومنها بين المذهبين.

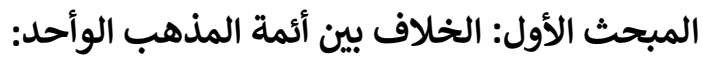

- ما ذكره في باب المهموز في وجوب قلب الهمزة الثانية إلى ياء إذا انكسر ما قبلها، والخلاف بين الخليل وسيبويه حول

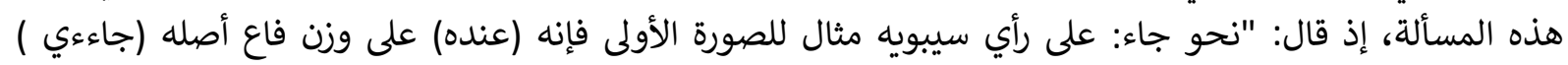

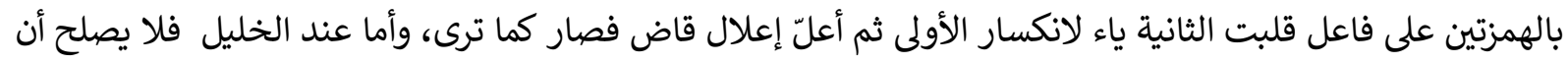

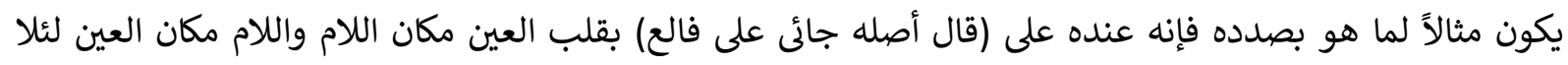
يجتمع همزتان، أعلّ إعلال قاض أيضاً"

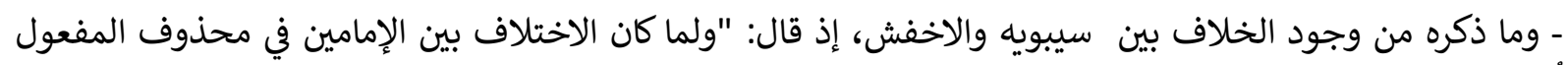

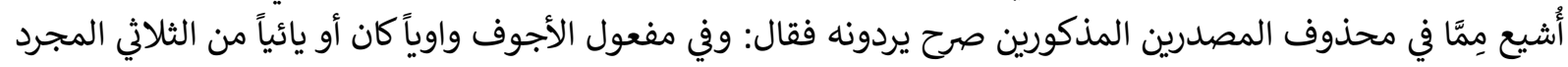

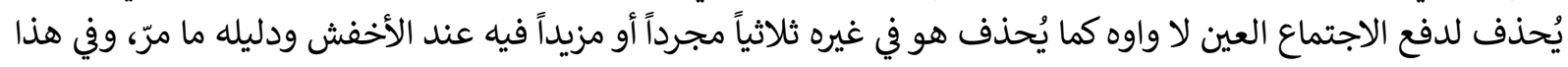

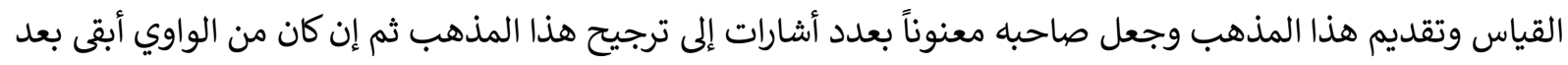

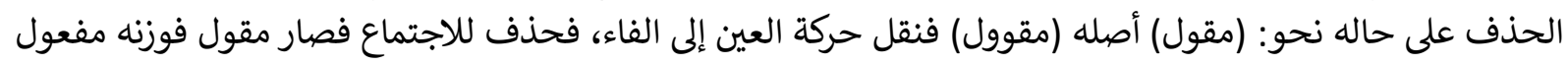

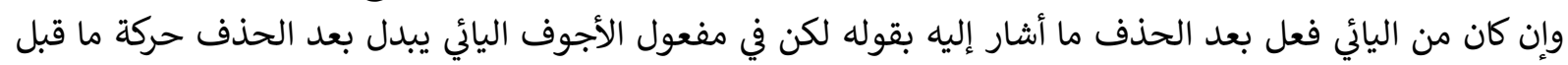

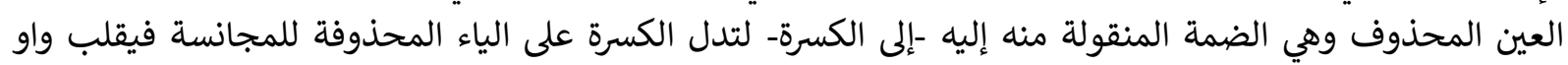

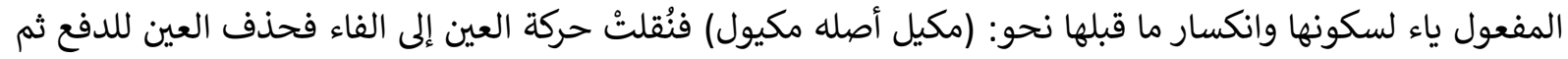

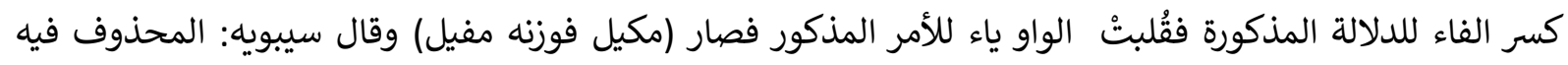

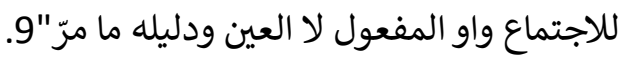


- ما أورده في مسألة حذف اللام الجازمة وابقاء عملها قوله: "إن الجازم الداخل عليهما لعدم دلالتهما بدونهما على التأل

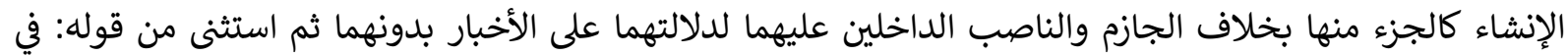

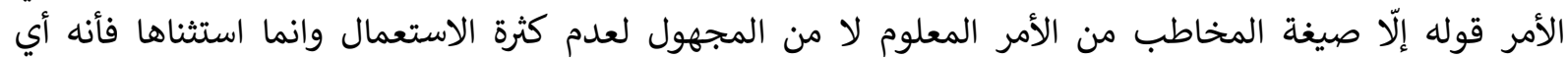

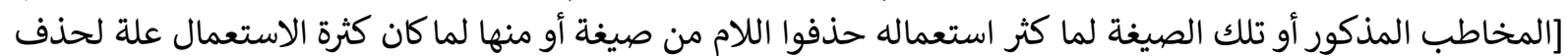

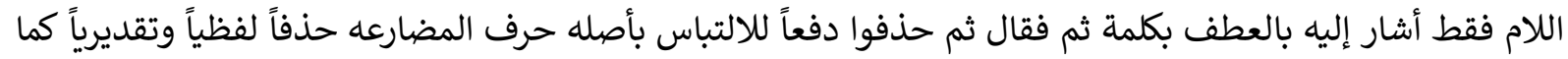

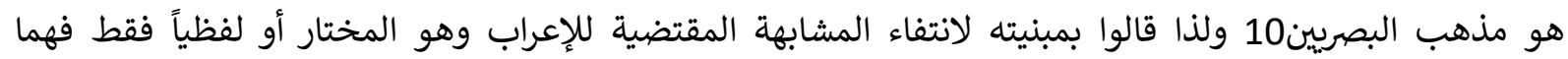

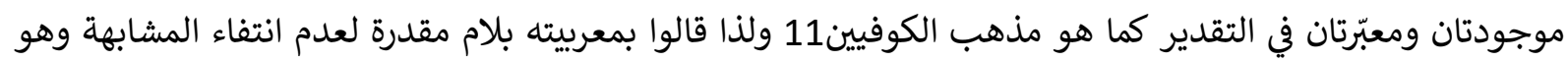

المرجوح"12.

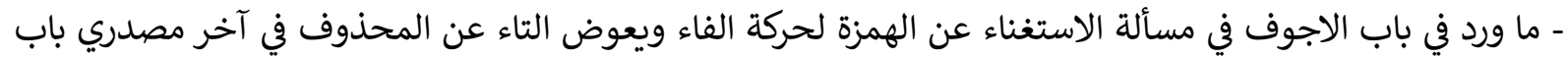

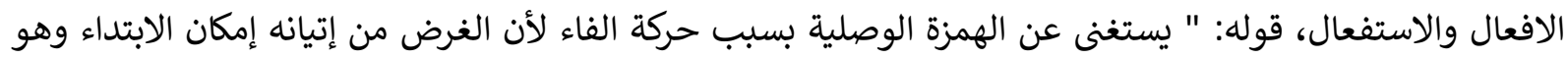

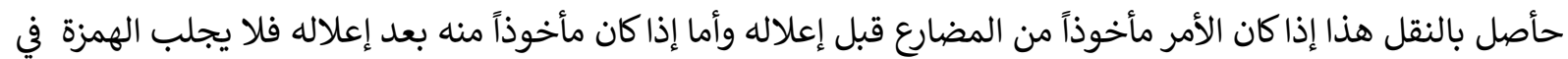

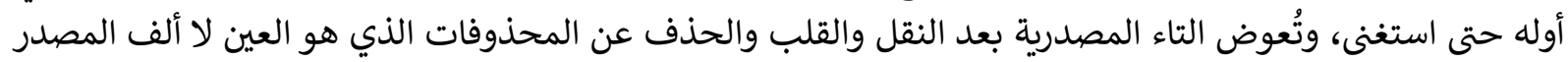

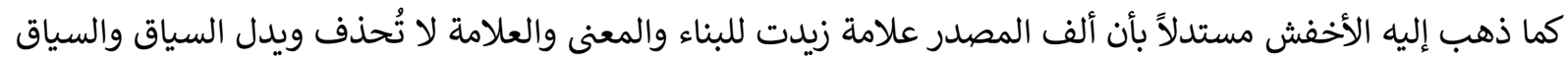

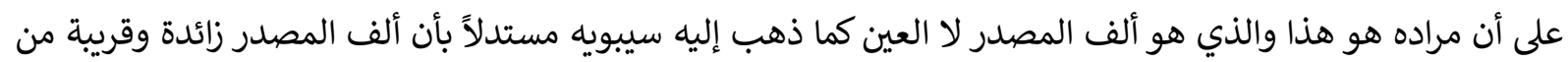

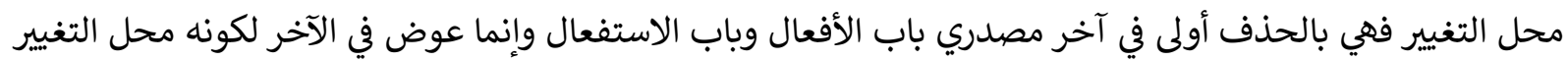

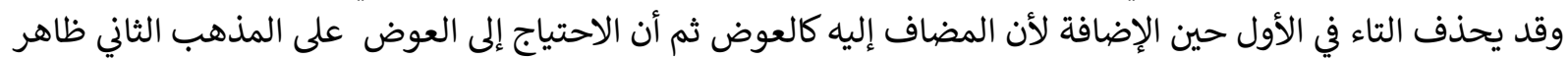

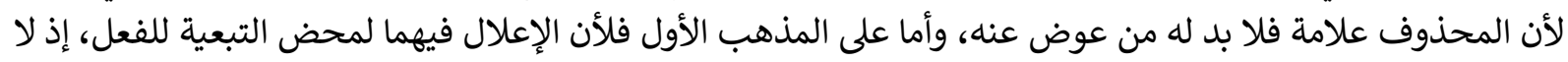

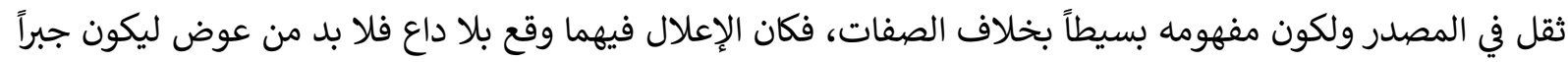

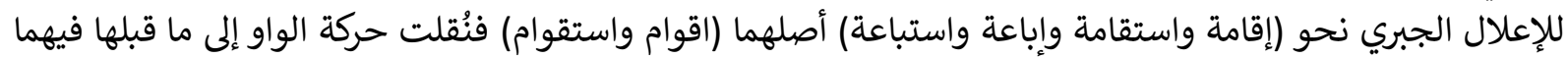

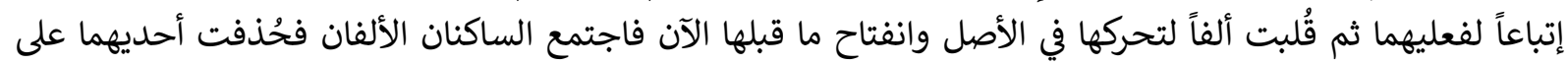

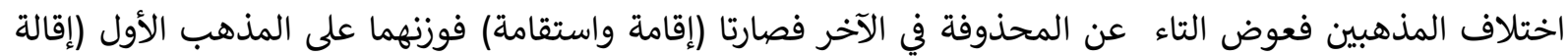
واستقالة)، وعلى الثاني (افعلة واستفعلة) "13.

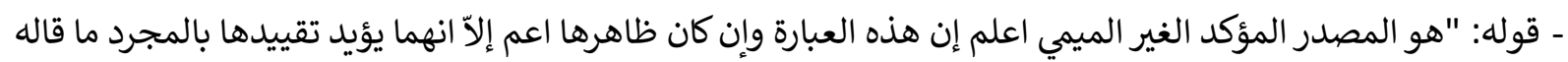

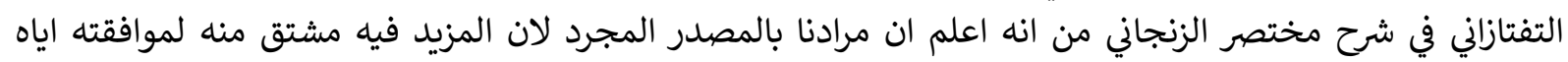

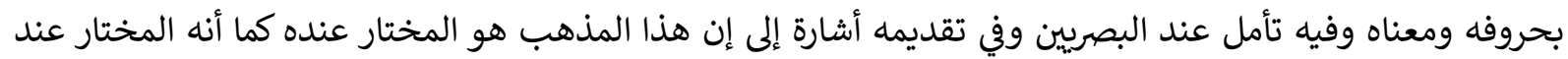

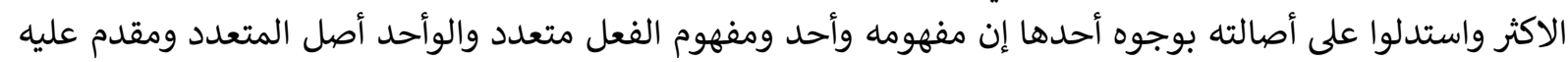

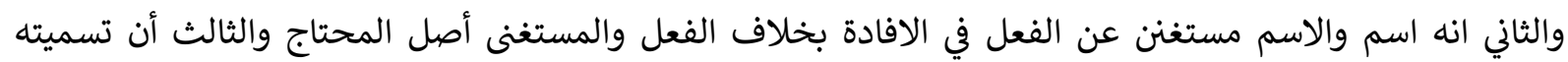

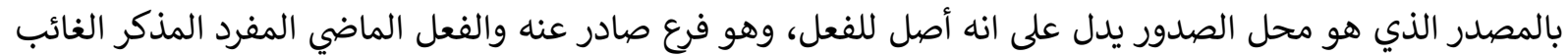

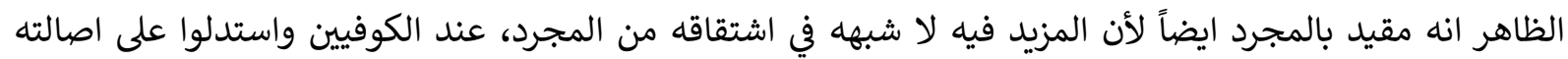

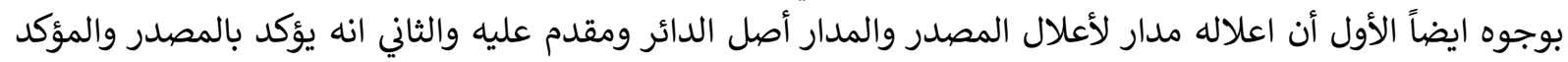

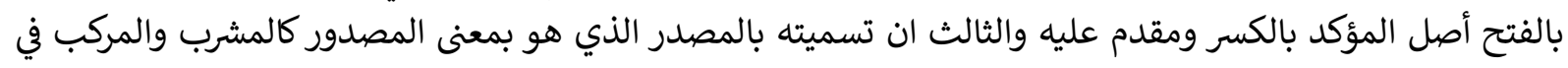

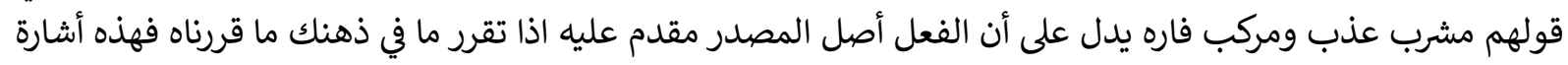
إلى التقسيمات الثلاثة السابقة"14.

ـ وقوله: "واما اسم مصدر أو مشتقاً ويجوز أن يكون المتعلق هو الحمد وان كان التقان بعيداً أو يحتمل أن يكون الباء زائداً فلا

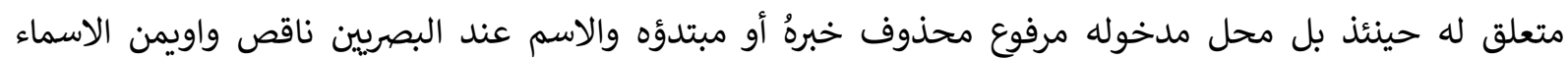

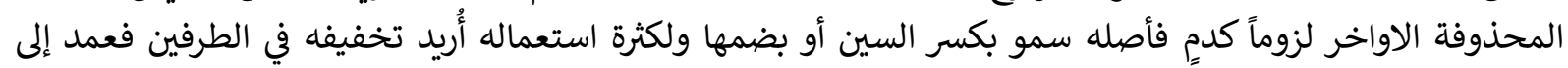

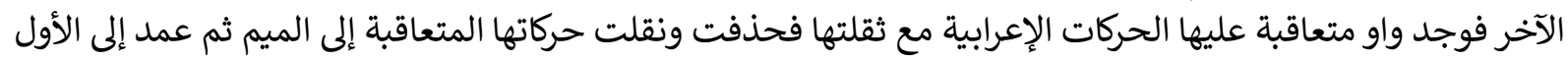


فحذف حركة السين لا لسين لئلا يحجف الكلمة ثم ادخلت همزة الوصل مكسورة لكون الابتداء بالساكن متعذراً أو

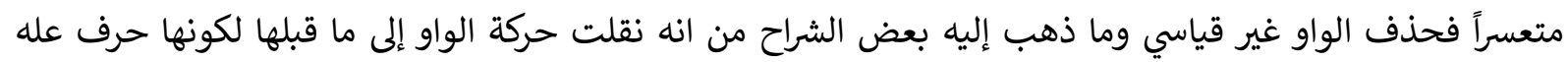

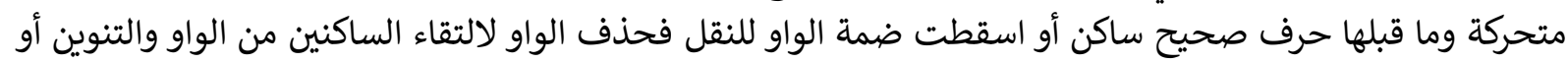

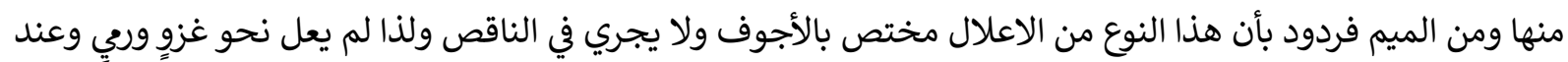

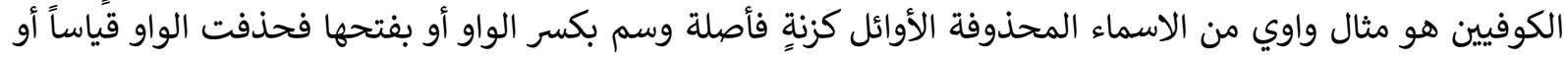

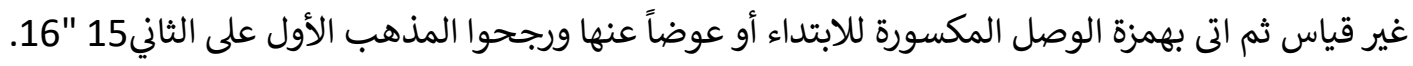

الخاتمة

الحَمْدُ للهِ الَّي يَسَّرَ بمنّه وفضْله وعوْنه على إتمام هذا البحث، ومن خلال الموضوعات التي ذكرت والتي سبق الحديث عنها وصلنا إلى أهم النتائج: 1. كان منهجه في التعامل مع المسائل الصرفية منهجاً تعليمياً، وما يمثل هذا المنهج قلة ذألة ذكره للمسائل الخلافية أو لا يذكر جميع الآراء في المسألة الخلافية الوأحدة.

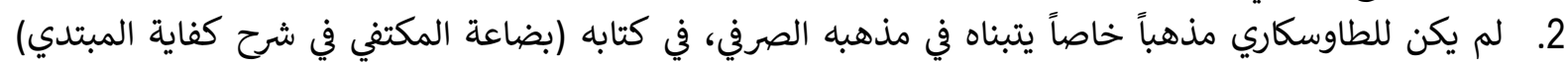

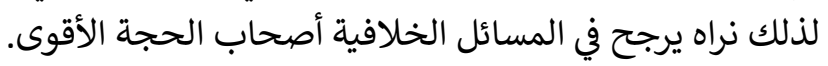

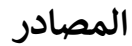

أخبار النحويين البصريين: الحسن بن عبد الله بن المرزيان السيرافي، أبو سعيد (المتوفى: 368هـ)، تح/ طه محمد الزيني،

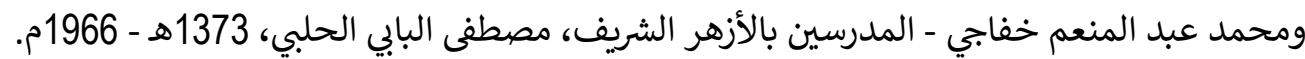

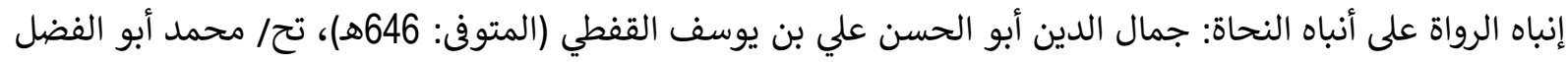

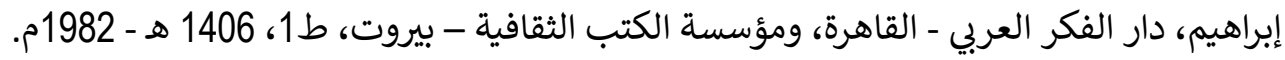

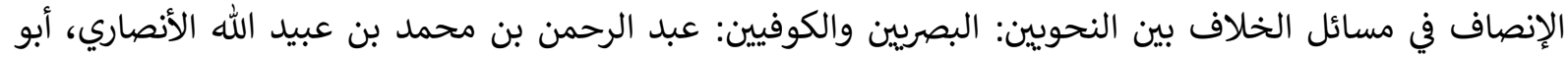

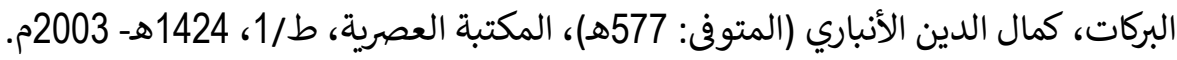

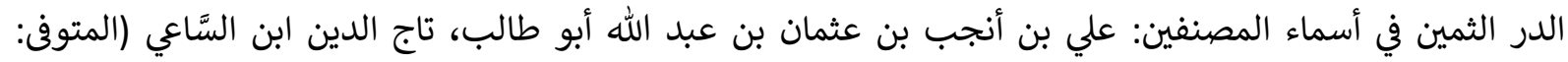

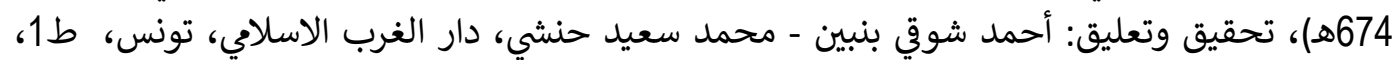

1430 هـ - 2009م. تحقيق وتعلم.

شرح المفصل لابن يعيش: موفق الدين يعيش بن علي بن يعيش النحوي (ت 646هـ)، تح/ الاستاذ الدكتور ابراهيم

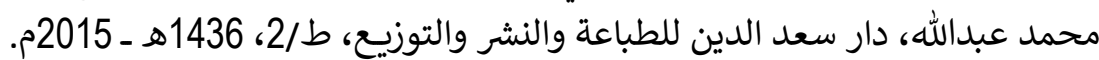

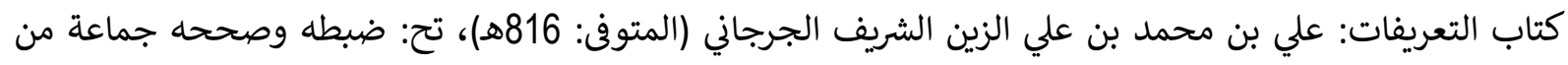

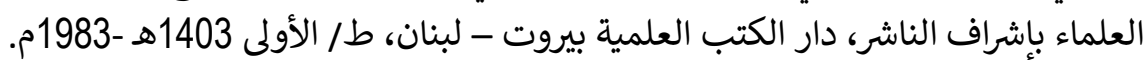

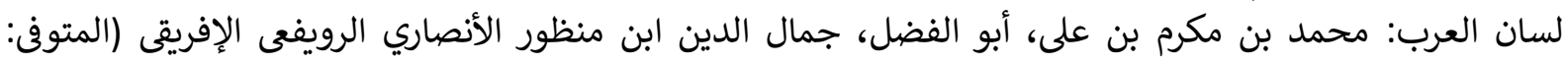

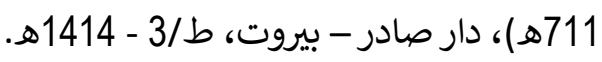

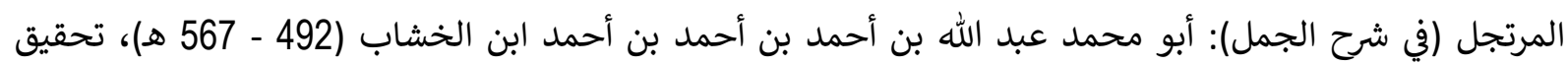

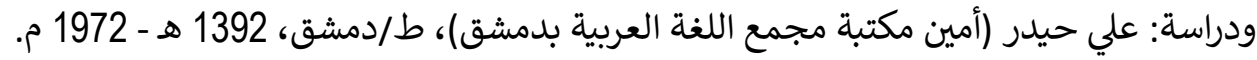

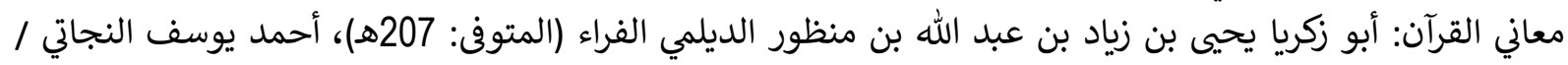

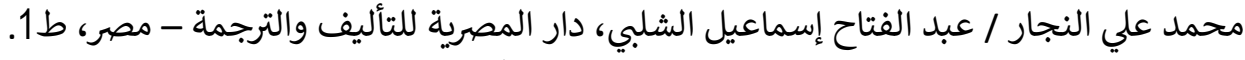

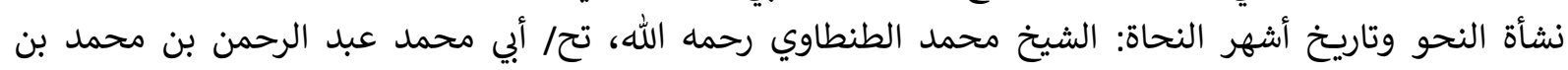

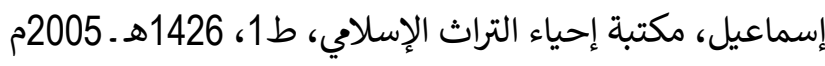




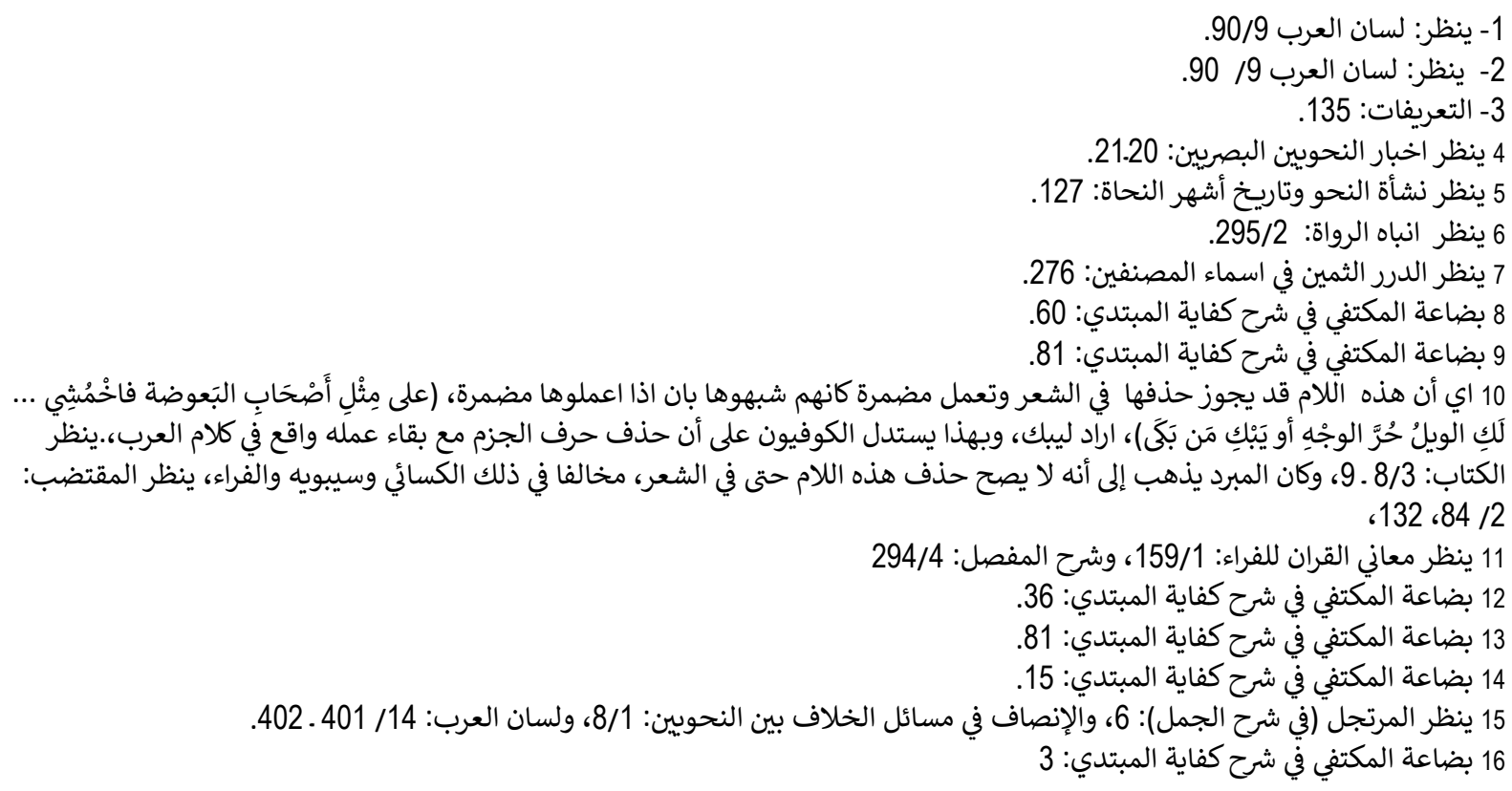

